\title{
NOVACIONES Y TRANSACCIONES SOBRE TIPOS DE INTERÉS USURARIO. OTRA VEZ CONTRA UNA TENDENCIA EQUIVOCADA*
}

\author{
Ángel Carrasco Perera** \\ Catedrático de Derecho Civil \\ Universidad de Castilla-La Mancha \\ Centro de Estudios de Consumo
}

Title: NOVATIONS AND TRANSACTIONS ON USURIOUS INTEREST RATES. AGAIN AGAINST A WRONG TREND

Resumen: La jurisprudencia Wizink de Juzgados y Audiencias viene sosteniendo no siempre, es cierto- la siguiente doctrina. Una vez que el contrato es nulo por usura, la nulidad se extiende a todo el contrato, incluso a los nuevos tipos de interés no usurarios que se hayan pactado después de una novación/transacción entre las partes, de modo que la entidad acreditante tendrá que restituir todos los intereses recibidos, incluso aquellos posteriores a la novación que intrínsecamente no eran usurarios, cuando el acreditado demande la nulidad del art. 3 de la Ley de Usura. Este trabajo contiene una crítica de este doctrina.

Abstract: The Wizink jurisprudence of Courts and Hearings has been upholding - not always, it is true - the following doctrine. Once the contract is void due to usury, the nullity extends to the entire contract, including the new non-usurious interest rates

\footnotetext{
* Trabajo realizado en el marco del Proyecto de Investigación PGC2018-098683-B-I00, del Ministerio de Ciencia, Innovación y Universidades (MCIU) y la Agencia Estatal de Investigación (AEI) cofinanciado por el Fondo Europeo de Desarrollo Regional (FEDER) titulado "Protección de consumidores y riesgo de exclusión social", del que soy Investigador Principal con la profesora Encarna Cordero Lobato; a la Ayuda para la financiación de actividades de investigación dirigidas a grupos de la UCLM Ref.: 2021-GRIN 31309, denominado "Grupo de Investigación del Profesor Ángel Carrasco" (GIPAC) y a la ayuda para la realización de proyectos de investigación científica y transferencia de tecnología, de la Junta de Comunidades de Castilla-La Mancha cofinanciadas por el Fondo Europeo de Desarrollo Regional (FEDER) para el Proyecto titulado "Protección de consumidores y riesgo de exclusión social en Castilla-La Mancha" (PCRECLM) con Ref.: SBPLY/19/180501/000333 del que soy Investigador Principal con la profesora Ana Isabel Mendoza Losana

** ORCID ID: https://orcid.org/0000-0003-3622-2791
} 
that have been agreed after a novation / transaction between the parties, so that the accrediting entity will have to restore all the interests received, even those after the novation that were not intrinsically usurious, when the borrower demands the nullity of art. 3 of the Usury Law. This work contains a critique of this doctrine.

Palabras clave: Jurisprudencia Wizink, novaciones, transacciones, tipos de interés, interés usurario.

Key words: Wizink jurisprudence, novations, transactions, interest rates, usurious interest.

\section{La mala ciencia}

Hace una semana se publicó en el número 39/2021 de la Revista CESCO de Derecho de Consumo un excelente trabajo de Alicia Agüero, que revisaba toda la jurisprudencia de Audiencias producida en aplicación de la Ley de Usura después de la STS 149/2020- Wizink. El trabajo es iluminador de la diversidad inexplicable de criterios entre los distintos juzgadores, de la aparente discrecionalidad de los estándares, pero también apunta una certidumbre de lo que en cada sitio se puede esperar dentro del caos.

El objeto de esta nota es el que sigue. La jurisprudencia Wizink de Juzgados y Audiencias viene sosteniendo - no siempre, es cierto- la siguiente doctrina. Una vez que el contrato es nulo por usura, la nulidad se extiende a todo el contrato, incluso a los nuevos tipos de interés no usurarios que se hayan pactado después de una novación/transacción entre las partes, de modo que la entidad acreditante tendrá que restituir todos los intereses recibidos, incluso aquellos posteriores a la novación que intrínsecamente no eran usurarios, cuando el acreditado demande la nulidad del art. 3 de la Ley de Usura.

Un ejemplo. Audiencia Provincial de Asturias (Sección 4a) Sentencia núm. 265/2021 de 1 julio, JUR 2021/280589 (la TAE era 26.82 y se bajó a 19,16 en 2019): "la recurrente sostiene también que toda vez que el tipo de interés inicial fue modificado en octubre de 2019, para aplicar un nominal del $18 \%$ (equivalente, dice al 19,16\% T.A.E.), habría de descartarse por igual la desproporción, o, cuando menos, hacerlo a partir de ese instante, entendiendo que se produjo una novación a la que no trascendería la nulidad inicial del contrato. Y aquí basta para desestimar el argumento considerar que con esa argumentación la recurrente cambia el planteamiento de la oposición que tenía formulada en la instancia, donde, no solo sostenía que ese tipo inferior era el que realmente se había pactado, sino que, además, no aludía a una fragmentación del contrato como la que ahora pretende, prescindiendo con ello de lo que impone el art. 456.10 de la Ley de Enjuiciamiento Civil. Ello sin perjuicio de recordar, como ha hecho esta Sala en múltiples resoluciones precedentes (así, sentencias de 29 y 16-4-2021, por citar las más recientes), que la apreciación de la usura comporta la nulidad radical del contrato desde el momento mismo de su 
celebración, sin una posibilidad de convalidación ulterior con una actuación que no permite fragmentar el contrato en distintas etapas para otorgar validez en parte a lo que es nulo desde su inicio, sin que se esté ( sentencia de 12-11-2020) ante una novación, que exigiría una nueva negociación y acuerdo de las partes ( arts. 1203 y concordantes CC, de las que nada aparece, y menos ante varios contratos a los que pudiera darse un tratamiento diverso ".

Parece que este argumento es empleado por igual cuando el tipo contractual no era usurario, pero el prestamista lo fue subiendo con el paso del tiempo, de forma que el tipo nuevo sí fuera usurario. Así la Audiencia Provincial de Asturias (Sección 4a) Sentencia núm. 283/2021 de 14 julio. JUR 2021/304196: "Asimismo de los extractos mensuales obrantes en autos se comprueba que desde la celebración del contrato hasta la mensualidad de marzo de 2019 en los casos que se aplicó la fórmula de pago revolving se aplicó una TAE de $21,84 \%$, dicho porcentaje no puede considerarse usurarios puesto que el índice específico de crédito mediante tarjetas de crédito y tarjetas revolving, publicado por el Banco de España en el mes de febrero de 2012 era del 20,374\%, por lo que no puede considerarse notablemente superior al interés normal del dinero. Pero a partir del mes de abril de 2019 se le empezó a aplicar una TAE del 22,28 \% y el índice específico de crédito mediante tarjetas de crédito y tarjetas revolving, publicado por el Banco de España en el mes de abril de 2019 es del 19,89\%, por tanto, el aplicado es notablemente superior al tipo medio para este tipo de operaciones - supera en más de dos puntos. Como ya señala esta Sala en sentencia no 300/20, de 16 de septiembre de 2020, la entidad alteró el contrato unilateralmente y fijó una nueva TAE del 22,28 \% como tipo de interés ordinario, que es claramente excesivo, siendo el tipo medio específico publicado por el Banco de España; (...). Sobre cómo puede incidir la modificación unilateral del tipo de interés en la declaración de nulidad por usura de un contrato, se ha pronunciado esta Sección en sentencias como las de 2 de mayo de 2019 o 10 de marzo y 7 de octubre de 2020 , para poner de manifiesto que no cabe fraccionar o parcelar en el tiempo un contrato que es único, pues resultaría absurdo que un mismo contrato pudiera ser válido y nulo al mismo tiempo en función del periodo de vigencia que se considere y del tipo de interés que durante el mismo se hubiera aplicado; lo que contemplan los arts. 1 y 3 de la Ley de Represión de la Usura es la nulidad total del contrato, y no solo la referida a un periodo de tiempo durante el que desplegó sus efectos. No se está ante una novación, que exigiría una nueva negociación y acuerdo de las partes (arts. 1203 y concordantes CC, de las que nada aparece, y menos ante varios contratos a los que pudiera darse un tratamiento diverso, sino ante un incremento unilateral realizado en desarrollo o aplicación de lo ya pactado, que en tanto posibilita elevadísimo interés debe merecer la sanción de nulidad por usura. Es decir, aunque se aceptase como válido el interés inicial, la conclusión final sería la misma acerca de la nulidad del contrato litigioso por causa de usura, razones que conducen a la desestimación del recurso ".

Parece que la fuente de estas ideas se encuentra en la STS de 14 julio 2009 que repitió la STS 25 noviembre 2015 (Sygma Mediatis): "La nulidad del préstamo 
usurario, claramente establecida por el artículo 1 de la Ley de 23 de julio de 1908, comporta una ineficacia del negocio que es radical, absoluta y originaria, que no admite convalidación confirmatoria, porque es fatalmente insanable, ni es susceptible de prescripción extintiva. Dicha nulidad afecta a la totalidad del convenio con la única consecuencia, establecida en el artículo 3, de que ha de retrotraerse la situación al momento inmediatamente anterior al préstamo, lo que determina que el prestatario haya de devolver la cantidad efectivamente recibida sin que para ello haya de tenerse en cuenta plazo alguno establecido para tal devolución, ya que su fijación queda comprendida en la ineficacia absoluta y total de lo convenido, lo que lleva aparejada la consecuencia de que, aun en el caso hipotético planteado por la parte recurrente de que se inste la nulidad del préstamo antes del cumplimiento del plazo fijado, la devolución por el prestatario de la cantidad recibida ha de ser inmediata".

\section{La novación}

¿Qué es contrato? La jurisprudencia aludida parte de una fijación dogmática. Dado que el "contrato de tarjeta" es el "contrato" de referencia, las "novaciones" (en sentido amplio), si no son extintivas del "contrato", son meros accesorios, dependencias, epígonos del "contrato". Mas si el "contrato" es nulo, reza el apotegma, han de serlo también todas sus dependencias, productos, accesorios, porque lo nulo no produce ningún efecto, como vuelve a afirmar la paremia escolar, tantas veces repetida como falseada. Pero "contrato" en el art. 1254 CC no es un nicho preestablecido donde se acumulan cláusulas hasta constituir un tipo complejo y cerrado. Contrato es en el art. 1254 CC cualquier acuerdo, con independencia de su extensión, por el que las partes contraen obligaciones de contenido determinado. No existe diferencia material entre cláusula y contrato. Claro que no es lo mismo la cláusula de un contrato que este contrato como suma de cláusulas. La parte no puede ser lo mismo que el todo. En efecto. Pero todo ello depende de cuál sea el horizonte de negociación de las partes en cada caso. Si las partes negocian un contrato de crédito mediante tarjeta, no hay contrato hasta que se han acordado todas las cláusulas pertinentes a este horizonte de negociación. Una cláusula aislada, aunque consentida, no hace contrato, no obliga, porque no es coextensa con el horizonte de negociación. Pero si el horizonte de negociación es precisamente y sólo una cláusula (la cláusula que contiene una novación), esta cláusula es contrato a los efectos del art. 1254 CC. Lo es a todos los efectos.

Aplicación. En consecuencia, a los efectos de sucesión contractual, una cláusula que resulta coextensa con su horizonte de negociación es, respecto del contrato preexistente, como si se tratara de un nuevo contrato. Si el contrato de tarjeta $X$ fuera entonces nulo por usurario, y las partes luego acordaran un nuevo contratosuma de cláusulas $Y$, que ya no fuera usurario, y este contrato contuviese una cláusula de derogación del preexistente, nadie dudaría que $Y$ no está infectado por la paremia quod nullum est, porque $Y$ no es producto, accesorio, epígono, fruto o escoria del contrato $X$, sino un contrato nuevo. Sería enorme sostener que, puesto que las partes han pactado un contrato usurario $X$, ya serán usurarios todos los contratos 
que quieran pactar en el futuro con el mismo objeto, pónganse las partes como quieran y digan lo que les parezca. Pero entonces no puede haber ninguna diferencia si, en lugar de tipo-suma de cláusulas, Y fuera una cláusula única de novación modificativa de $X$, siempre que $Y$ tenga su propia causa, su propio objeto, y sea coextensa con su horizonte de negociación. En tal caso, $Y$ estará fuera de la espiral maldita de que nullitas accessorii sequitur nullitas principalis.

La porfía en no entender el art. 1208 CC. Como el derecho se estudia y se transmite boca a boca en píldoras de paremias autosignificativas, es dificilísimo convencer a un operador (bienintencionado), que cabalga a lomos de su derecho básico construido sobre brocardos, incluso de la verdad más elemental. Digo esto a propósito del art. 1208 CC, que, siempre que hay ocasión, vuelve a interpretarse de la peor manera. Hay veces que uno piensa que es mejor no aprender derecho que aprenderlo mal. Este precepto no está diciendo, evidentemente, que la novación de un contrato nulo sea nula. Si así fuera la cosa, habría que sostener también, conforme a la lógica ya explicada, que todo contrato que siga en el tiempo a un contrato nulo, y verse sobre materia equivalente, es también nulo. Es notorio que la cláusula o el contrato novatorio sólo será nulo si adolece del mismo vicio que hacía nulo el primero, pero no si lo subsana. O si adolece de otro vicio distinto que también lo haga nulo.

Un segundo predicado ceteris paribus del art. 1208. La norma se formula con esta restricción implícita expuesta, que nadie puede negar. La norma contiene, empero, un segundo predicado, que no se refiere a la nulidad del título, sino a sus efectos. Este predicado reza así: aunque el título nuevo pueda regular válidamente los efectos nuevos, el título nuevo no sirve para dotar retroactivamente de validez a los efectos (nulos) que ya se habían producido merced al título viejo. El art. 1208 viene entonces a afirmar que la sanación novatoria no produce efectos retroactivos. Pero tal predicado no es más que una formulación de principio, que vale sólo ceteris paribus. Depende del contenido de la conducta significativa de las partes. Todos los ejemplos de confirmación expresa de contratos anulables constituyen excepciones a la regla de la no retroactividad de efectos. ¿Es posible que esto ocurra también en los contratos nulos radicalmente? Depende de los casos, porque no todas las nulidades son iguales. La novación pura de futuro no puede hacer que no fueran usurarios los intereses ya devengados y pagados, pero la novación pura de futuro puede hacer que estos intereses pagados no sean restituibles y se capitalicen, por ejemplo, al crédito nuevo como capital disponible libre de intereses; no puede discutirse la licitud de tal pacto. Un contrato nulo por ilicitud causal consistente en propósito de dañar a terceros admite una retroacción validadora de efectos si luego el tercero confirma (no "ratifica") el contrato. La nulidad consistente en la falta de una autorización externa previa se sana normalmente con la emisión posterior de aquélla. Los efectos que no produjo en el tiempo un contrato simulado pueden llegar a ser producidos retroactivamente si las partes lo confirman. ¿Por qué puede confirmarse un contrato anulable por dolo y no puede confirmarse un contrato nulo por pretenderse con él dañar a una persona? 
Excurso sobre este último ejemplo. Aunque este trabajo no trata de simulaciones contractuales, me interesa despejar las dudas que pudiera haber suscitado el último ejemplo que acabo de citar. A y B declaran que venden y compran, contrato simulado y nulo, que acaso esconde, o no, un subyacente contrato disimulado válido, por ejemplo, una fiducia cum amico. Pasa el tiempo y las partes están de acuerdo en "confirmar" o "convalidar" el contrato simulado, pagando precio por la cosa, y acuerdan retrotraer los efectos a la fecha del acuerdo inicial; por ejemplo, que B pague intereses desde la fecha a quo. Se dirá: no hay efectos retroactivos, y $B$ sólo adquiere el dominio desde ahora, y los intereses retrospectivos carecen de causa. Mas se comprende que se trata de una porfía antinatural. Si la operación estaba inscrita y las dos partes están de acuerdo en que el dominio pasara a B a la fecha del título simulado ¿quién podrá desautorizar esta intención, tanto más cuanto todos los efectos derivados de la apariencia (incluso el pago de impuestos) estaban apoyados en la creencia de la validez de la venta simulada? Desde el momento en que nadie puede fundar una pretensión basada en la confianza sobre la nulidad anterior, claro resulta que está en el imperio de las partes causar con su nueva declaración un efecto retroactivo, porque la nulidad de origen no sirve ya a ninguna causa.

El art. 1208 CC y las novaciones de las cláusulas suelo. Hay ya cerca de un centenar de sentencias del TS que repiten que las cláusulas suelo nulas por intransparentes pueden novarse pro futuro válidamente, si la cláusula que contiene la novación satisface a su vez los requerimientos de la transparencia material. No importa detallar en este lugar cuáles son estos requerimientos, si bien la jurisprudencia parece estar ya muy estabilizada al respecto, asumiendo y desarrollando los postulados de la STJUE 9 julio 2020 (cfr. SSTS 580/2020, 63/2021, 581/2020, 208/2021, 309/2021, 340/2021，530/2021，6434/2021，647/2021)， aunque la doctrina buena es anterior a esta sentencia europea (cfr. SSTS 205/2018, $489 / 2018,548 / 2018,101 / 2019$ ). Estas sentencias citadas, y otras muchas de 2020 y 2021 , tienen como denominador común que estiman recursos de casación contra sentencias de Audiencias que habían sostenido pertinazmente que una cláusula suelo nula no podía ser novada válidamente. Por tanto, el art. 1208 CC, que se había convertido en un caballo de batalla en manos de fundamentalistas, ha sido desarticulado como objeción a la verdad de lo obvio. Si la cláusula novatoria no incurre en la causa de nulidad que es la falta de transparencia material, es una cláusula que no está afectada por la paremia (falsa) de la secuencia fatal de las nulidades. Dado que esta jurisprudencia superior está (para bien de la justicia) ya consolidada, no puede existir ninguna razón para seguir aplicando la paremia perversa a las cláusulas de novación pro futuro de contratos usurarios de tarjeta, si el nuevo tipo de interés pactado no es usurario; en otros términos, si la novación como contrato (al ser coextensa con su horizonte de negociación) no incurre en el mismo vicio que hacía nulo el contrato preexistente.

Conclusión. Es seguro que las resoluciones judiciales son bienintencionadas (acaso no todas), pero la porfía de los juzgadores acaba cegándoles y les impele a cometer la perversidad de declarar nulos los nuevos intereses no usurarios y obligar a 
devolverlos también al pagador cuando se declara la nulidad del contrato usurario y la restitución de sus efectos previos a la novación. Esta doctrina no puede estar justificada por ninguna regla de derecho ni por ninguna metafunción del Derecho de usura en virtud de la cual los jueces debieran castigar en todo lo posible a los contratantes que impusieron un tipo de interés que un juzgador consideró luego usurario.

Una vez más: ¿qué es contrato? La jurisprudencia de adverso, que se citó, no sólo negaba la capacidad novatoria en los términos expuestos. Negaba que pudiera hablarse de novación en una simple modificación unilateral del tipo de interés (a la baja). No era ni siquiera "contrato", sino arbitrio. Esto es notoriamente un error, como puede comprobarse leyendo los supuestos de alteración unilateral de contratos financieros a que se refiere el art. 85.3 de la LGDCU. La legitimación del predisponente para acometer la modificación unilateral en cuestión proviene de contrato. Si el contrato prevé esta facultad, su extensión y sus límites, el resultado de su ejercicio correcto vale finalmente como parte del contrato. No se puede pretender que el nuevo tipo de interés (a la baja) vincula a las partes en méritos de una declaración unilateral de voluntad. Igual que la renta arrendaticia actualizada por el arrendador vale en su condición de contrato (si la actualización es correcta), y como incumplimiento de contrato se sanciona su impago. Además, añado una segunda consideración. El art. 85.3 LGDCU pone límite al derecho potestativo unilateral porque supone que las alteraciones son en daño de la contraparte consumidora. Pero si una parte del contrato propone una modificación unilateral que beneficia a la parte destinataria, esta oferta vale como contrato sin necesidad de aceptación (así lo dice el Código Civil italiano); o, cuando menos, si se ha aceptado concluyentemente por el simple hecho de seguir operando con la tarjeta.

\section{La transacción}

De la novación a la transacción. Un pacto de eliminación pro futuro de una cláusula suelo o de reducción de un tipo de interés en contrato de tarjeta es una cláusula meramente novatoria. Una cláusula en la que, como contraprestación por esta ventaja sobrevenida, el consumidor renuncia correspectivamente a ejercitar las acciones de nulidad que le hubiera correspondido por el contrato originario, es una transacción, con el matiz que luego introduzco ${ }^{1}$. La transacción no procederá si la cláusula sobre la que se transige ya había sido declarada anula (STS 421/2021).

\footnotetext{
1 "La primera cláusula, por sí sola, y al margen de la tercera, constituye una modificación o novación de la cláusula suelo. Y la tercera, en cuanto contiene una renuncia al ejercicio de acciones, tiene su causa en la reducción de la cláusula suelo, de forma que ambas constituyeran los dos elementos esenciales de un negocio transaccional: el banco accede a reducir el suelo y los clientes, que en ese momento podían ejercitar la acción de nulidad de la originaria cláusula suelo, renuncian a su ejercicio" (STS 647/2021). Previamente he escrito sobre este asunto en http://centrodeestudiosdeconsumo.com/images/Sentencia europea intransparente sobre una transacc ion transparente de una clausula suelo supuestamente intransparente.pdf http://centrodeestudiosdeconsumo.com/images/Validez de las novaciones transaccionales de presta mos hipotecarios con clausula suelo.pdf;

http://centrodeestudiosdeconsumo.com/images/Transaccion sobre clausula suelo.pdf
} 
Como bien explicaba la STS 205/2018, "Los contratos de 2014 no son novaciones, sino transacciones, con causa propia y suficiente, la de evitar una controversia judicial sobre la cláusula suelo originaria. El contrato es válido si tiene por objeto eliminar la incertidumbre mediante concesiones recíprocas. No existe inconveniente en transigir sobre una cláusula que podría ser nula - de existir juicio- por falta de transparencia. La transacción no contraviene tampoco la ley, porque la controversia recae sobre materia disponible. Se cita en apoyo determinada jurisprudencia relativa a la validez de transacciones habidas entre empresarios y consumidores (interesa destacar, por lo interesante, el supuesto que se resolvió en la STS 459/2017, sobre cantidades adelantadas en la compra de vivienda futura). Aunque la transacción se haya realizado también mediante cláusulas predispuestas, existen datos que abonan que en el presente se ha respetado por el banco el deber de transparencia: "en un contexto temporal en que, por la difusión en la opinión pública general de la sentencia de 9 de mayo de 2013, era notoriamente conocido no sólo la existencia de estas cláusulas suelo y su incidencia en la determinación del interés variable aplicable al préstamo, sino también que podían ser nulas cuando no se hubieran cumplido las exigencias de la transparencia, los clientes aceptan la propuesta del banco de impedir futuras controversias judiciales al respecto mediante la reducción del suelo al 2,25\% y para acreditarlo transcriben de su puño y letra (...)". Toda transacción que contenga una renuncia a acciones de nulidad ceñidas al contrato originario es una transacción válida que contiene una renuncia válida, con efectos retroactivos (cfr., entre las últimas, STS 675/2021).

El art. 86.7 LDCU no ofrece un argumento. Por tres razones. Como sabemos, este precepto declara la nulidad de la cláusula no negociada por la que el consumidor renuncia a los derechos que le concede la normativa específica de consumidores. Por tanto, si en la negociación sucesiva se contiene una renuncia a las acciones contra el contrato originario, se incurriría en la prohibición del art. 86.7. Mas no es así. Primero, porque en este estado del procedimiento las cláusulas "transaccionales" necesariamente han de ser cláusulas negociadas y por tanto exoneradas de control de contenido. Segundo, porque el consumidor no puede renunciar anticipadamente a sus derechos como consumidor, y toda renuncia por medio de una cláusula se reputa prohibida por ser una renuncia anticipada. Pero la renuncia en 2014 a las acciones de 2007 es una renuncia que recae sobre un derecho ya adquirido, y una renuncia que el consumidor no tiene por qué aceptar - como tendría que haberla aceptado en 2007- si quería acceder al préstamo hipotecario, que era la esencia de su interés. La renuncia no versa, pues, sobre una ventaja que es el quid pro quo de la contraprestación a la que el prestatario aspira. El consumidor puede renunciar al ejercicio de un derecho adquirido; y con más razón si por esta renuncia le dan precio. Observemos que nada estamos proponiendo en el sentido de que esta renuncia transaccional sea una especie de "convalidación" de la falta de transparencia original, como algún recalcitrante podría imaginar aupándose ahora sobre el falso techo que sería el art. 1208 CC. La tercera razón, porque la operación es una transacción. "Prometer" y "retener" es la estructura sinalagmática de la transacción en el art. 1809 CC. Existe una incertidumbre de quien ganaría el pleito, y ambos ganan con el 
trato, pero no todo lo que quisieran haber ganado, en un acuerdo que evita el pleito y reparte el riesgo o la desventaja. La transacción no versa tampoco sobre ninguna de las materias prohibidas por el art. 1814 CC (iuna nulidad a instancia de parte no es sustancia intransigible!). Las renuncias transaccionales no pueden estar en el art. 86.7, entre otras cosas porque no parece factible un contrato transaccional no negociado. Además, es algo que se entiende de suyo como una verdad de Perogrullo, como resulta de estos dos ejemplos. Pepe dispone de una acción de saneamiento para que le reparen el vehículo comprado con defectos; pacta con el empresario que en lugar de proceder a la reparación acepta una indemnización y renuncia a demandar. Pepe puede pedir la resolución del contrato porque el promotor no le entregó aval o seguro por cantidades adelantadas; las partes acuerdan que Pepe renuncia a la acción a cambio de que se le rebaje el precio de la vivienda. Observemos, y esto es lo más conspicuo, que estas dos transacciones son indiscutiblemente válidas, aunque se hallan perfeccionado por medio de contratos de adhesión, salvo que el consumidor pruebe un vicio de consentimiento que anula el contrato, no una "abusividad" que anule la cláusula (de hecho, no hay "cláusula" como tal).

Novación de la cláusula suelo y novación del tipo de interés de la tarjeta Ya en este asunto se produce un desliz. Pues yo creo que las "condiciones de transparencia" exigibles a la cláusula novada no son las condiciones de transparencia exigibles a la cláusula novante. "Arriba" no hay una cláusula suelo, sino una renuncia parcial del banco a la cláusula suelo a cambio de un compromiso del cliente de no impugnar la cláusula suelo. Arriba no se exigen condiciones de transparencia que sean propias de la cláusula suelo original, sino las que son propias de un intercambio transaccional. De la cláusula suelo, el cliente sólo ha de saber arriba que, con una probabilidad casi rayana en la certeza, la cláusula suelo es nula: el cliente transige sobre la incertidumbre de que esa cláusula sea nula, y para eso no necesita saber de nuevo los factores $X$ e $Y$ que en origen hubieran hecho que la cláusula suelo resultara transparente y no nula. El quid de la transacción no es la cláusula suelo que se nova, sino su rebaja como tal.

Transparencia versus contraste objetivo. El predicado de nulidad por usura no es un predicado de falta de transparencia sino un contraste objetivo entre estándar de precio permitido y estándar de precio prohibido, sin que importen las condiciones en que el acuerdo se celebró, especialmente a partir de que la jurisprudencia ha decidido prescindir de las condiciones subjetivas de nulidad del art. 1 Ley de Usura en el análisis de las nulidades por usura de los tipos de interés en tarjetas revolving. Es, pues, un escenario distinto del de las cláusulas suelo. Era inevitable que en las novaciones de cláusulas suelo se planteara, amenazante y perturbador, el problema de cómo podía considerarse transparente una cláusula que novaba otra cláusula prima facie no transparente. Era difícil evitar 'la sospecha de la continuidad de la falta de transparencia. En las cláusulas de intereses revolving no hay un problema parecido. En la medida en que todo el asunto trata del salto de un estándar 
cuantitativo nulo a un estándar cuantitativo válido, el juicio de contraste puede realizarse sin arrastrar consigo la pesada carga de la nulidad preexistente.

Transparencia en transacción revolving. El hecho de que el control de usura no constituya un control comprendido en el ámbito material y competencial de las Directivas armonizadas 1993/13 y 2008/48 (STJUE, Sala Sexta, de 25 de marzo de 2021) no quiere decir que los contratos relativos a operaciones al consumo, que sean susceptibles de usura, no estén comprendidos en el ámbito de cobertura de la Directiva. Una transacción novatoria de un tipo de interés es un contrato de consumo sujeto al test de transparencia material. En este punto no difieren usura y cláusula suelo. Pero son distintos los métodos para satisfacer las exigencias de transparencia material en uno y otro caso. Se trata en ambos casos de conocer la "carga jurídica y económica" que el acuerdo comporta para el consumidor. En el presente caso, el consumidor ha de saber cuánto podría importar la devolución si instara con éxito la nulidad. La averiguación es más fácil que en la cláusula suelo, pues las cantidades afectadas son todas las pagadas en concepto de intereses. En realidad, no se exigiría de la entidad un desvelamiento de tal cosa, pues la cifra de intereses ha de constar en los justificantes de pago. En todo caso, para no divagar sobre un problema de hecho, el consumidor debe de saber cuánto podría recuperar si demandara con éxito la nulidad del contrato. Obviamente, la entidad no tiene que informar ni evaluar en beneficio del consumidor la cifra de probabilidad de que su demanda fuera estimada, porque el riesgo jurídico no forma parte de la carga que integra el deber de información. Pero tampoco puede ocultar la realidad ni minimizar el riesgo, porque ambas conductas hacen intransparente la cláusula transaccional.

El quid pro quo transaccional. Una cláusula suelo puede ser nula por falta de transparencia material, pero no por la cifra en la que esté determinado el suelo. Una cláusula suelo del $3 \%$ no es ni más ni menos nula, ni más ni menos intransparente, que una cláusula suelo anclada en el 1,5\%. Cuando la entidad "ofrece" al cliente una bajada de la cláusula del 3 al 1,5, a cambio de la renuncia transaccional a la nulidad preexistente, no pretende con ello situarse en la frontera de lo lícito objetivo, sino procurar a su cliente una ventaja, que servirá de contraprestación transaccional. No importa que ahora esté ofreciendo la entidad a sus clientes nuevos un tope de suelo del 1.5. Al pasar del 3 al 1,5, el cliente consigue una ventaja, porque la entidad está renunciando a una expectativa de suelo 3 que sólo sería inválida si la contratación original no hubiera satisfecho el estándar de transparencia material. O mejor, la expectativa de suelo 3 es objetivamente válida de suyo, porque la cláusula suelo es válida en sentido material en cualquiera de sus rangos. El cliente transacciona ahora detrás de un velo de la ignorancia del que ya no podrá salir una vez que la transacción esté acordada. Nunca llegará a saber si su contratación fue o no transparente. Reparemos la sutil diferencia con el supuesto de novación del tipo revolving. Aquí sí es materialmente decisivo pasar de 3 a 1,5, porque las condiciones de validez material son distintas. Es cierto que si el cliente transige ya no podrá saber nunca si hubiera vencido en el pleito de nulidad por usura. Pero en el horizonte de incertidumbre hay una diferencia: para saber si la cláusula suelo era no transparente 
hubiera sido en todo caso preciso litigar el caso concreto; para saber el tope de la usura no, porque es objetivamente predecible para cada jurisdicción, de acuerdo con lo que expusimos al inicio de este trabajo: basta acudir a la tabla construida por Alicia Agüero. Al margen del proceso individual podemos saber al menor en teoría si un tipo de 3 es usurario o no. Es un extremo de validez objetiva. Y por esto también su tratamiento debe ser más severo que el de la cláusula suelo transigida. Entiendo que la transacción quedaría incompleta por falta de causa (quid pro quo transaccional, art. 1809 CC) si la entidad se limita a ofrecer, a cambio de la renuncia, las mismas condiciones de tipo de interés no usurario que está ahora ofreciendo a sus clientes nuevos. No ignoro que la jurisprudencia (no consumerista) viene actuando laxamente en lo referido a los requisitos de correspectividad exigidos en la transacción. Pero esta jurisprudencia no puede valer en pleitos en los que la contraparte es un consumidor, porque en tales casos la transacción queda reconvertida en renuncia simple, y esta se halla condenada por el art. 86.7 LGDCU. La entidad tiene que mejorar de manera no irrelevante la posición futura de la contraparte de la transacción, si quiere obtener causa onerosa que soporte la renuncia como transacción. La ventaja puede ser de cualquier tipo, ni tan siquiera es preciso que esté incorporada al contrato. Puede ser, como ocurrió en la transacción consumerista de STS 446/2020 [reclamación al asegurador de la devolución de cantidades aplazadas en la compraventa de vivienda], una ventaja del pronto pago. Puede ser incluso una reducción del riesgo jurídico; quiere decir, según las circunstancias del caso, el riesgo de incertidumbre sobre la cifra del techo de usura puede ser considerable, lo bastante como que la eliminación de ese riesgo (de perder, se entiende) constituya una contraprestación suficiente para asentar la transacción. En todo caso, no se trata de una cuestión de concepto, sino de grado. Y en el estado presente de nuestra jurisprudencia - que cambiaría con una tercera decisión casacional que incrementara la incertidumbre- creo que no constituye un quid pro quo suficiente para sanar el pasado la mera reproducción de las condiciones de mercado pactadas con clientes nuevos fuera de la usura. 